\title{
The importance of minor salivary gland biopsy in prediction of lymphoma in Sjögren's syndrome: should we be obtaining more information about prognosis from minor salivary gland samples?
}

\author{
Robert I Fox
}

Theander, ${ }^{1}$ in this issue, provides an important contribution with the article 'Lymphoid organization in labial salivary gland biopsies is a possible predictor for the development of malignant lymphoma in primary Sjögren's syndrome'. It has been known for many years that ectopic germinal centres are present in minor salivary gland biopsies of a subpopulation of patients with Sjögren's syndrome (SS). The frequency of SS patients with an ectopic germinal centre in the minor salivary gland biopsy has ranged from $10 \%$ to $25 \% .^{2-4}$ Previous studies by Jonsson and his research group have described the clinical and laboratory characteristics of SS patients with ectopic germinal centres in their minor salivery gland biopsies. ${ }^{5-9}$ Other groups have also used histology, immunohistology and gene profiling to characterise the ectopic germinal centre in SS. ${ }^{10-14}$ In the current paper, the frequency of ectopic germinal centres was somewhat lower than in previous publications. The goal has been to determine the risk of B cells undergoing transition from benign lymphoproliferation to overt malignancy. ${ }^{15}$

The current study ${ }^{1}$ extends those studies by emphasising the increased risk of lymphoma in SS patients whose minor salivary gland biopsy contains an ectopic germinal centre. This is not a new concept, because an association between ectopic germinal centre formation and lymphoma development in primary SS was initially proposed in $1999 .{ }^{16}$ Despite the important prognostic information to be gained from a more detailed analysis

Correspondence to: Robert I Fox, Rheumatology Clinic, Scripps Memorial Hospital-XIMED Medical Group, Suite \#910, 9850 Genesee Avenue, La Jolla, CA 92037, USA; robertfoxmd@mac.com of the minor salivary gland biopsy, most rheumatologists in the USA do not obtain biopsies, and oral pathologists do not routinely examine them critically for the presence of ectopic germinal centres. At present, the minor salivary gland biopsy is used in the USA predominantly either in the research setting or as an 'obligation' to fulfil SS criteria in the patient lacking antibody to SS-A or SS-B. The current article emphasises the need for rheumatologists to obtain minor salivary gland biopsies as a method to predict the risk of lymphoma and for the pathologist to read the biopsy with attention to ectopic germinal centres as well as focus score.

In addition to routine histology, the detection of ectopic germinal centres may be improved by the use immunohistology to detect both particular subsets of B cells and dendritic cells. Monoclonal antibodies have also been used to evaluate the types of cells in the lip biopsy, although generally on a research basis ${ }^{17}$ for over 25 years. However, we have not established uniform guidelines for oral pathologists to use histological stains or immunohistology to evaluate B cells and dendritic cells in minor salivary gland biopsies.

The importance of this article is that it challenges us to 'move on' from the current method of evaluation of the minor salivary gland biopsy using routine histology simply to 'count lymphocytes' and calculate focus scores. The key take-home message of this article would include, at a minimum, the reporting of lymphoid organisation/germinal centre-like structures in the lip biopsy by pathologists. In view of the importance of the detection of ectopic germinal centres in minor salivary gland biopsies, we should strongly advocate for guidelines to pathologists that identify germinal centres and their associated lymphoid/dendritic cells. It would appear that many talented and perhaps overworked pathologists are not aware of the rudimentary methods to evaluate and grade minor salivary gland biopsies from SS patients. All too often, rheumatologists receive the rather useless report 'no evidence of cancer' and not even the report of a calculated focus score. As we establish patient registries to improve prognosis and guide therapies, minor salivary gland samples must be collected, processed and evaluated in a uniform manner to allow comparison of results from different cohorts of patients.

In other medical specialties, biopsies of lymph nodes or breast tumours routinely employ 'special immunohistological stains' for prognosis and establishment of therapy. This paper raises the question of whether we are getting maximal information from minor salivary gland biopsies in rheumatology. The strong association of germinal centre-like structures with a higher risk of lymphoma provides an important clinical incentive for rheumatologists to demand a more detailed report of the minor salivary gland biopsy. In addition, the added knowledge of the pathogenesis derived from understanding of these 'extraglandular' lymphoid infiltrates will help us move forward with novel treatments by identifying subsets of SS patients. ${ }^{18}$

From a critical point of view, the article by Theander ${ }^{1}$ in this issue does have the significant limitations of a retrospective study, ascertainment bias of a tertiary institution, a relatively small number of patients and the lack of associations that would be expected from other published studies for lymphoma risk in SS. The incidence of lymphoma in SS patients has been estimated to be $5-10 \%$ of patients (or higher with long-term follow-up), ${ }^{19} 20$ representing an increased risk that has ranged from six to 44 -fold. ${ }^{21-25}$ Some predictors have been repeatedly documented from large patient cohorts, namely hypocomplementaemia, persistent or recurrent salivary gland swelling and cutaneous vasculitis or palpable purpura with hazard ratios for low complement factor 4 (C4) levels of up to 9.5 by Theander et al. ${ }^{26}$ These results confirmed the importance of low C4 levels and palpable purpura at first presentation as markers of high risk for lymphoma in primary SS. ${ }^{23}$ The current study by Theander $^{1}$ did detect an association 
with low C4 levels but not with palpable purpura. The lack of association of ectopic germinal centres, lymphoma and other expected risk factors is most likely due to the limited number of lymphomas $(n=7)$ included in the study. Also, it is important to note that the other classic risk factors, including cryoglobulin, sustained parotid enlargement and a history of palpable purpura, were not assessed in all patients of the cohort in the present study. Therefore, the ability to draw strong conclusions about relative risk of a single variable such as germinal centres is very much limited by ascertainment bias of which tests are ordered. The only way to avoid this bias is to examine a cohort prospectively in which all patients have all the tests.

A clear explanation of why germinal centre-like structures in the biopsy should indicate or even facilitate lymphoma development has not been provided-germinal centre-like structures may represent an incidental finding. However, a 'simple' but reasonable hypothesis might be that lymphocytes and dendritic cells are generated (or mature) with the expression of particular homing receptors that see cognate 'ligands' expressed on a subset of high endothelial venules in characteristic tissues. For example, mucosal lymphocyte homing receptors for B cells were well described over 20 years ago in mucosal lymphomas, with a more recent description of specific homing receptors on high endothelial venules for $\mathrm{T}$ cells and dendritic cells. These homing receptors have been associated with the development of extranodal lymphomas. ${ }^{27-30}$

Indeed, it is reasonable to propose that various subsets of SS patients generate lymphoid and dendritic cells with characteristic homing receptors. The ability of homing receptors for cells capable of forming germinal centres would predispose to lymphoma, because the proximity of particular dendritic and lymphoid elements in the tissue will lead to mutual expansion and eventual neoplastic transformation of B cells. Also, autoantibody expressed by $B$ cells in germinal centres may play an important role in the perpetuation of immune stimulation by T cells and dendritic cells in response to immune complex and further perpetuation of stimulatory cytokine release. ${ }^{31-34}$ The lip biopsy can thus be viewed as a convenient and safe source of tissue to make prognostic and therapeutic decisions, as well as the elucidation of the interface between immune stimulation and lymphoproliferation.
In summary, this paper emphasises that the detection of germinal centrelike structures in a minor salivary gland biopsy is important in clinical decisionmaking. For the rheumatologist, we must obtain the biopsy more frequently as part of the database for prognostic purposes. Furthermore, it is time to set specific guidelines to instruct pathologists in a standardised method of routine microscopy, special histological stains and perhaps immunohistology to detect ectopic germinal centres. Then we will be able to correlate these histological data with prognosis and response to therapy. Now that we have emerging therapies for the depletion of particular lymphocyte subsets and modulation of cytokines, including B-cell factors and T-regulator cells, we must learn to identify subsets of SS patients, and the most obvious method will be based on better extraction of information from minor salivary gland tissue biopsies.

\section{Competing interests None.}

Provenance and peer review Commissioned; externally peer reviewed.

Accecpted 6 June 2011

Ann Rheum Dis 2011;70:1351-1353

doi:10.1136/ard.2011.152751

\section{REFERENCES}

1. Theander E. Lymphoid organisation in labial salivary gland biopsies is a possible predictor for the development of malignant lymphoma in primary Sjögren's syndrome. Ann Rheum Dis 2011;70:1363-8.

2. Greenspan JS, Daniels TE, Talal N, et al. The histopathology of Sjögren's syndrome in labial salivary gland biopsies. Oral Surg Oral Med Oral Pathol 1974;37:217-29.

3. Adamson TC, 3rd, Fox RI, Frisman DM, et al. Immunohistologic analysis of lymphoid infiltrates in primary Sjogren's syndrome using monoclonal antibodies. J Immunol 1983:130:203-8.

4. Ramos-Casals M, Brito-Zeron P, Yagü J, et al. Hypocomplementaemia as an immunological marker of morbidity and mortality in patients with primary Sjögren's syndrome. Rheumatology 2005; $44: 89$

5. Salomonsson $\mathbf{S}$, Jonsson MV, Skarstein K, et al. Cellular basis of ectopic germinal center formation and autoantibody production in the target organ of patients with Sjögren's syndrome. Arthritis Rheum 2003;48:3187-201.

6. Jonsson MV, Szodoray P, Jellestad S, et al. Association between circulating levels of the novel TNF family members APRIL and BAFF and lymphoid organization in primary Sjögren's syndrome. J Clin Immunol 2005:25:189-201.

7. Jonsson MV, Skarstein K, Jonsson R, et al. Serological implications of germinal centerlike structures in primary Sjögren's syndrome. J Rheumatol 2007:34:2044-9.

8. Reksten TR, Jonsson MV, Szyszko EA, et al. Cytokine and autoantibody profiling related to histopathological features in primary Sjogren's syndrome. Rheumatology (Oxford) 2009;48:1102-6.
9. Jonsson MV, Skarstein K. Follicular dendritic cells confirm lymphoid organization in the minor salivary glands of primary Sjögren's syndrome. J Oral Pathol Med 2008;37:515-21.

10. Stott DI, Hiepe F, Hummel M, et al. Antigen-driven clonal proliferation of $B$ cells within the target tissue of an autoimmune disease. The salivary glands of patients with Sjögren's syndrome. J Clin Invest 1998;102:938-46.

11. Hjelmervik T0, Petersen K, Jonassen I, et al. Gene expression profiling of minor salivary glands clearly distinguishes primary Sjögren's syndrome patients from healthy control subjects. Arthritis Rheum 2005;52:1534-44.

12. Hansen A, Lipsky PE, Dörner T. B cells in Sjögren's syndrome: indications for disturbed selection and differentiation in ectopic lymphoid tissue. Arthritis Res Ther 2007:9:218.

13. Daridon C, Pers JO, Devauchelle V, et al. Identification of transitional type II B cells in the salivary glands of patients with Sjögren's syndrome. Arthritis Rheum 2006;54:2280-8.

14. Larsson A, Bredberg A, Henriksson G, et al. Immunohistochemistry of the B-cell component in lower lip salivary glands of Sjögren's syndrome and healthy subjects. Scand J Immunol 2005;61:98-107.

15. Jonsson R, Nginamau E, Szyszko E, et al. Role of B cells in Sjögren's syndrome - from benign lymphoproliferation to overt malignancy. Front Biosci 2007:12:2159-70.

16. Voulgarelis $\mathbf{M}$, Dafni UG, Isenberg DA, et al. Malignant lymphoma in primary Sjögren's syndrome: a multicenter, retrospective, clinical study by the European Concerted Action on Sjögren's Syndrome. Arthritis Rheum 1999:42:1765-72.

17. Fox RI, Carstens SA, Fong S, et al. Use of monoclonal antibodies to analyze peripheral blood and salivary gland lymphocyte subsets in Sjögren's syndrome. Arthritis Rheum 1982:25:419-26.

18. Konttinen YT, Sorsa T, Hukkanen M, et al. Topology of innervation of labial salivary glands by protein gene product 9.5 and synaptophysin immunoreactive nerves in patients with Sjögren's syndrome. J Rheumatol 1992;19:30-7.

19. Sutcliffe N, Inanc M, Speight P, et al. Predictors of lymphoma development in primary Sjögren's syndrome. Semin Arthritis Rheum 1998;28:80-7.

20. Theander E, Manthorpe R, Jacobsson LT. Mortality and causes of death in primary Sjögren's syndrome: a prospective cohort study. Arthritis Rheum 2004;50:1262-9.

21. Kassan S, Talal N. Sjögren's syndrome with systemic lupus erythematosus/mixed connective tissue disease. In: Talal N, Moutsopoulos HM, Kassan SS, eds. Sjögren's Syndrome: Clinical and Immunological Aspects. Berlin: Springer Verlag, 1987:177-81.

22. Smedby KE, Hjalgrim $\mathrm{H}$, Askling J, et al Autoimmune and chronic inflammatory disorders and risk of non-Hodgkin lymphoma by subtype. J Natl Cancer Inst 2006:98:51-60.

23. Ioannidis JP, Vassiliou VA, Moutsopoulos HM. Long-term risk of mortality and lymphoproliferative disease and predictive classification of primary Sjögren's syndrome. Arthritis Rheum 2002; 46:741-7.

24. Brito-Zerón P, Ramos-Casals M, Nardi N, et al. Circulating monoclonal immunoglobulins in Sjögren syndrome: prevalence and clinical significance in 237 patients. Medicine (Baltimore) 2005;84:90-7.

25. Brito-Zerón P, Ramos-Casals M, Bove A et al. Predicting adverse outcomes in primary Sjogren's syndrome: identification of prognostic factors. Rheumatology (Oxford) 2007:46:1359-62. 
26. Theander E, Henriksson G, Ljungberg 0, et al. Lymphoma and other malignancies in primary Sjögren's syndrome: a cohort study on cancer incidence and lymphoma predictors. Ann Rheum Dis 2006:65:796-803.

27. Dogan A, Du M, Koulis A, et al. Expression of lymphocyte homing receptors and vascular addressins in low-grade gastric B-cell lymphomas of mucosa-associated lymphoid tissue. Am J Pathol 1997:151:1361-9.

28. Drillenburg P, van der Voort R, Koopman G, et al. Preferential expression of the mucosal homing receptor integrin alpha 4 beta 7 in gastrointestinal non-Hodgkin's lymphomas. Am J Pathol 1997; 150:919-27.
29. Raderer M, Streubel B, Woehrer S, et al. High relapse rate in patients with MALT Iymphoma warrants lifelong follow-up. Clin Cancer Res 2005;11:3349-52.

30. Brandtzaeg $\mathbf{P}$, Johansen FE. Mucosal B cells: phenotypic characteristics, transcriptional regulation, and homing properties. Immunol Rev 2005;206:32-63.

31. Martin T, Weber JC, Levallois $\mathrm{H}$, et al. Salivary gland lymphomas in patients with Sjögren's syndrome may frequently develop from rheumatoid factor B cells. Arthritis Rheum 2000;43:908-16.

32. Mariette X. Lymphomas complicating Sjögren's syndrome and hepatitis $\mathrm{C}$ virus infection may share a common pathogenesis: chronic stimulation of rheumatoid factor B cells. Ann Rheum Dis 2001;60:1007-10

33. Bende RJ, Aarts WM, Riedl RG, et al. Among B cell non-Hodgkin's lymphomas, MALT lymphomas express a unique antibody repertoire with frequent rheumatoid factor reactivity. J Exp Med 2005;201:1229-41.

34. Bende RJ, van Maldegem F, van Noesel CJ. Chronic inflammatory disease, lymphoid tissue neogenesis and extranodal marginal zone B-cell lymphomas. Haematologica 2009:94:1109-23. 